\title{
"Kiss-and-Run" Glutamate Secretion in Cultured and Freshly Isolated Rat Hippocampal Astrocytes
}

\author{
Xiaoke Chen, ${ }^{1,2}$ Liecheng Wang, ${ }^{1,2}$ Yang Zhou, ${ }^{1,2}$ Liang-Hong Zheng, ${ }^{1,2,3}$ and Zhuan Zhou ${ }^{1,2,3}$ \\ ${ }^{1}$ Institute of Molecular Medicine, Peking University, Beijing 100871, China, ${ }^{2}$ Institute of Neuroscience, Shanghai Institutes for Biological Sciences, Chinese \\ Academy of Sciences, Shanghai 200031, China, and ${ }^{3}$ State Key Laboratory of Biomembrane Engineering, College of Life Sciences, Peking University, Beijing \\ 100871, China
}

Under physiological conditions, astrocytes not only passively support and nourish adjacent neurons, but also actively modulate neuronal transmission by releasing "glial transmitters," such as glutamate, ATP, and D-serine. Unlike the case for neurons, the mechanisms by which glia release transmitters are essentially unknown. Here, by using electrochemical amperometry and frequency-modulated singlevesicle imaging, we discovered that hippocampal astrocytes exhibit two modes of exocytosis of glutamate in response to various stimuli. After physiological stimulation, a glial vesicle releases a quantal content that is only $10 \%$ of that induced by nonphysiological, mechanical stimulation. The small release event arises from a brief $(\sim 2 \mathrm{~ms})$ opening of the fusion pore. We conclude that, after physiological stimulation, astrocytes release glutamate via a vesicular "kiss-and-run" mechanism.

Key words: kiss-and-run; fusion pore; amperometry; single-vesicle FM imaging; glutamate; freshly isolated astrocyte

\section{Introduction}

Glial cells, including astrocytes, oligodendrocytes, and Schwann cells, have generally been considered passive components in the nervous system. Recently emerging evidence indicates that astrocytes, by releasing signaling molecules that include glutamate (Glu) and ATP, may also play active roles in various neural functions including neurogenesis, synaptogenesis, and synaptic modulation and plasticity (Carmignoto, 2000; Bezzi and Volterra, 2001; Haydon, 2001; Ullian et al., 2001; Fields and StevensGraham, 2002). One way in which astrocytes respond to neuronal activity is via activation of their membrane receptors, elevation of $\left[\mathrm{Ca}^{2+}\right]_{\mathrm{i}}$, and then release of glutamate to modulate synaptic plasticity. The mechanisms by which astrocytes release glutamate has been intensively studied (Carmignoto, 2000; Haydon, 2001). Recently, by using total internal reflection fluorescence (TIRF) microscopy, Bezzi et al. (2004) showed that vesicular release does occur in cultured astrocytes. Their study revealed that the vesicular glutamate release is $\mathrm{Ca}^{2+}$ and soluble $N$-ethylmaleimide-sensitive attachment protein (SNAP) receptor (SNARE) dependent. However, because of the limitations of TIRF, four major questions remain concerning the vesicular release of glial transmitters. (1) What are the detailed kinetics of the quantal transmitter release during fusion between vesicle and

Received April 26, 2005; revised Aug. 22, 2005; accepted Aug. 23, 2005.

This work was supported by National Basic Research Program of China Grants G2000077800 and 2006 CB500800 and National Natural Science Foundation of China Grants 30330210, 303328013, and C010505. We thank Drs. Shumin Duan and Zhijun Zhang, who have helped with this work in many respects. We thank Dr. Min Zhou for advice on freshly isolated astrocytes, Xiao-Yuan Zhu for the cell cultures, and Drs. lain Bruce, Yu-Tian Wang, and Ye-Guang Chen for reading this manuscript.

Correspondence should be addressed to Dr. Zhuan Zhou, Institute of Molecular Medicine, Peking University, Beijing 100871, China. E-mail: zzhou@pku.edu.cn.

DOI:10.1523/JNEUROSCI.1640-05.2005

Copyright $\odot 2005$ Society for Neuroscience $\quad$ 0270-6474/05/259236-08\$15.00/0 plasma membrane? (2) Does the vesicle release all ("full fusion") or only part of its content ("kiss-and-run") during a release event? (3) What type of vesicle (310 vs $30 \mathrm{~nm}$ in diameter) is responsible for the $\mathrm{Ca}^{2+}$-triggered release? (4) Does the $\mathrm{Ca}^{2+}$ dependent vesicle release exist not only in cultured but also in freshly isolated astrocytes? Clearly, these critical questions about glial transmitter release cannot be answered using TIRF.

Several techniques allow the recording of single-vesicle activity in real time. Micro-carbon fiber electrodes (CFEs) are used to record the release of easily oxidizable monoamines (catecholamines and serotonin) from adrenal chromaffin cells, mast cells, and neurons (Wightman et al., 1991; Chow et al., 1992; Zhou and Misler, 1995a). At a holding potential of 500-800 mV, this electrochemical assay, termed amperometry, permits high temporal (in milliseconds) and spatial (in micrometers) resolution recording of the kinetics of vesicular release (Zhou et al., 1996). Application of amperometry can be extended to cells without native monoamines by preloading their vesicles with serotonin or dopamine (Zhou and Misler, 1996; Kim et al., 2000; Zhang and Zhou, 2002). Single-vesicle release can also be detected by imaging vesicles preloaded with fluorescent styryl dyes (Angleson et al., 1999; Aravanis et al., 2003). After stimulation, the preloaded dyes are discharged from single vesicles, and this can be recorded by confocal microscopy. This optical method has very high spatial resolution $(<1 \mu \mathrm{m})$.

In the present work, we examine the kinetics of stimulusinduced vesicular release in cultured as well as freshly isolated astrocytes. We demonstrate that astrocytes release glutamate via two secretion modes from the large vesicles ( $310 \mathrm{~nm}$ in diameter) in response to different types of stimulation. Surprisingly, in response to physiological stimulation, astrocytes release their vesicular contents via a kiss-and-run mechanism. 


\section{Materials and Methods}

Cell culture and immunocytochemistry. Purified hippocampal astrocytes were obtained from postnatal day 1 (P1) Sprague Dawley rats (Shanghai SLAC Laboratory Animal Co., Shanghai, China), maintained in lowdensity primary culture, and used after 7-20 d in culture (Yang et al., 2003; Zhang et al., 2003). Freshly isolated astrocytes were obtained from rat (P10-P15) hippocampal slices (Zhou and Kimelberg, 2000, 2001) and were used for FM dye destaining experiments within $1 \mathrm{~h}$. For immunostaining, cultures were stained with anti-GFAP antibody (Chemicon, Temecula, CA) and fluorescence-conjugated secondary antibody antirabbit-IgG-FITC (Jackson ImmunoResearch, West Grove, PA), as described previously (Yang et al., 2003). The specificity of the GFAP antibody was confirmed with mixed cultures of astrocytes and neurons (Yang et al., 2003). In Figure 4B, AM1-43 (Biotium, Hayward, CA), a fixable fluorescent dye, was preloaded into the astrocytes. After washout of AM1-43 and culture medium, cells were fixed and subjected to permeabilization with $0.1 \%$ Triton $\mathrm{X}-100$ for $45 \mathrm{~min}$ at $4^{\circ} \mathrm{C}$. Then, the rabbit anti-glutamate antibody (Sigma, St. Louis, $\mathrm{MO}$ ) was added to the fixed astrocytes. Cyanine 5-conjugated anti-rabbit-IgG (Chemicon) was used to visualize the glutamate content of vesicles. Excess antibody was removed and cells were imaged using a Zeiss (Oberkochen, Germany) LSM 510 confocal microscope.

The use and care of animals in this study complied with the guidelines of the Animal Advisory Committee at the Shanghai Institutes for Biological Sciences.

Dopamine loading and electrophysiology. Purified astrocytes were loaded in a bath solution containing $70 \mathrm{~mm}$ dopamine (DA) for $45 \mathrm{~min}$ at $37^{\circ} \mathrm{C}$ (Zhang and Zhou, 2002). Ascorbate (1.2\%) was added to protect against DA oxidation. After DA loading, the astrocytes were washed five times with standard external solution. The loading of DA had little effect on the $\mathrm{Ca}^{2+}$ signals in response to glutamate stimulation (Glu-stim; data not shown). Control solutions and drugs were puffed locally onto the cell during recording via a multichannel microperfusion system (Zhang and Zhou, 2002). The cell was stimulated by either physiological chemical reagents (e.g., glutamate) or mechanically. The mechanical stimulation (Mstim) was applied by poking the astrocyte for $1-2 \mathrm{~s}$ with a micropatch-pipette (Araque et al., 1999). After Mstim, the cell membrane appeared to seal immediately, leaving no leak, because the elevated $\left[\mathrm{Ca}^{2+}\right]_{\mathrm{i}}$ returned to resting level in the presence of thapsigargin (data not shown). All data were collected and analyzed by a computer using IGOR software (WaveMetrics, Lake Oswego, OR). Mean \pm SEM was calculated, and the paired $t$ test was applied to determine significance $\left({ }^{\star *} p<0.01\right)$.

Amperometry. Highly sensitive, low-noise, carbon fiber electrodes (ProCFE; Dagan, Minneapolis, MN) were used for electrochemical monitoring of quantal DA release from astrocytes. The amperometric current $\left(I_{\text {amp }}\right)$ was measured at $780 \mathrm{mV}$ using a patch-clamp amplifier (Zhang and Zhou, 2002) (PC-2C; INBIO, Wuhan, China). Amperometric signals were low-pass filtered at $0.3 \mathrm{kHz}$ and digitized at $1 \mathrm{kHz}$. To increase the contact area between the flat glial cell and the CFE, the 5- $\mu \mathrm{m}$ diameter sensor tip was abraded to form a $45^{\circ}$ angle using a beveller (EG44; Narishige, Tokyo, Japan). For the tetanus toxin (TeNT) experiment shown in Figure 5, astrocytes from the same preparation were divided into two groups (with and without TeNT), and both were incubated at $37^{\circ} \mathrm{C}$ for $24 \mathrm{~h}$; the number of release events within 1 min were counted for statistics.

$F M$ and $\left[\mathrm{Ca}^{2+}\right]_{i}$ imaging. Astrocytes were treated with $100 \mu \mathrm{M}$ glutamate and $10 \mu \mathrm{M}$ FM 1-43 dye or $50 \mu \mathrm{M}$ FM 2-10 for 5 min, and then washed 10 times. FM was excited at $800 \mathrm{~nm}$ by a Zeiss LSM 510 twophoton upright microscope, and destaining was sampled at $1 \mathrm{~Hz}$. Fura-2 was excited at $760 \mathrm{~nm}$ laser, which activates $\mathrm{Ca}^{2+}{ }_{\text {-sensitive fura- } 2 \text { via }}$ two-photon effect (equivalent to single photon of $380 \mathrm{~nm}=760 / 2 \mathrm{~nm}$, with F380 as emission signal). For combined FM and $\mathrm{Ca}^{2+}$ recording, astrocytes were preloaded with $2 \mu \mathrm{M}$ fura-2 AM for $45 \mathrm{~min}$ before FM loading. Two-photon laser stimulation $(800 \mathrm{~nm}, 0.5 \mathrm{~mW}, 25 \times 25$ pixels $)$ was used to mimic Mstim in the FM imaging experiments. The laserinduced photobleach at the stimulation site was not counted in Figure 3. In some experiments, the nucleus served as a photon-section marker to adjust the focal plane before and after laser stimulation. For intracellular
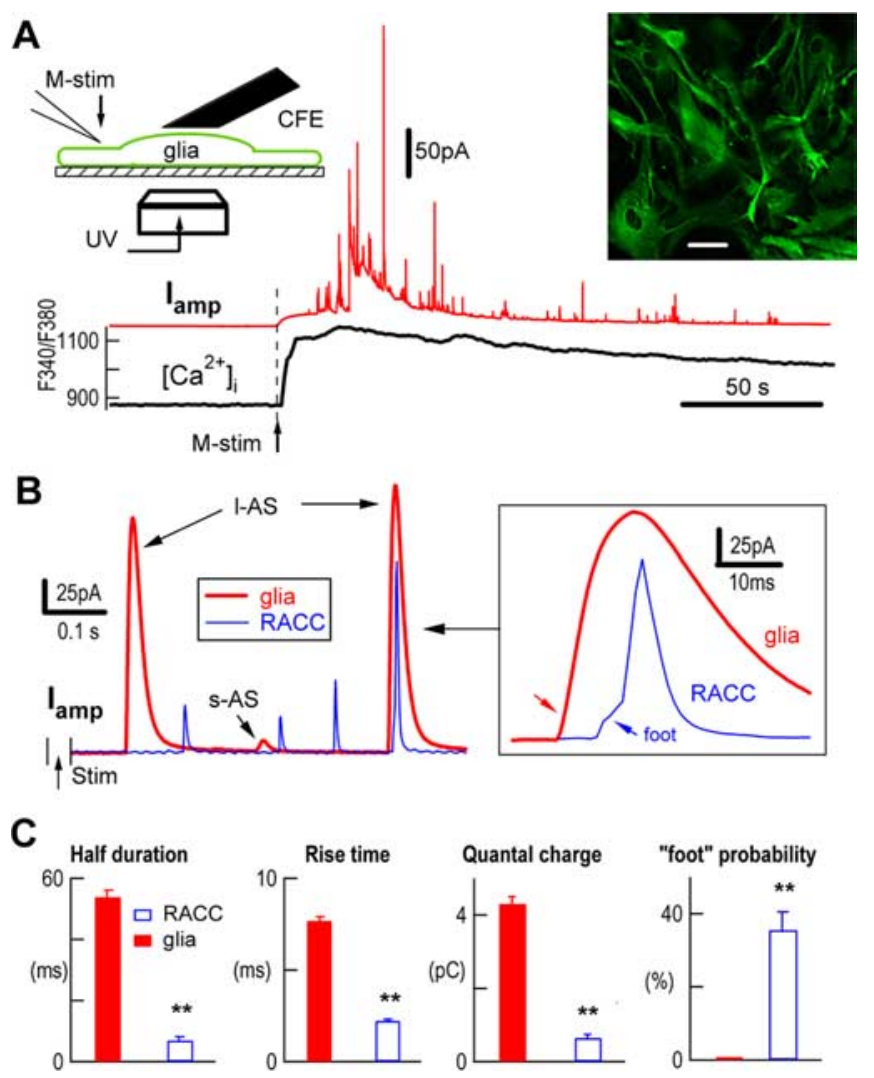

Figure 1. Stimulus-induced quantal secretion in astrocytes preloaded with dopamine. $\boldsymbol{A}$, Mstim (M-stim)-induced $\left[\mathrm{Ca}^{2+}\right]_{i}$ changes and amperometric spikes $\left(I_{\text {amp }}\right)$ in astrocytes. GFAP immunostaining of astrocytes (right). Scale bar, $20 \mu \mathrm{m}$. The diagram shows the experimental protocol (typical of (FE recording from $>100$ cells). $\boldsymbol{B}$, Superimposed $I_{\text {amp }}$ traces of glial and RACC ASs. Two classes of glial ASs are marked as s-AS and I-AS. Inset, Glial I-AS and RACC AS at expanded time scale. C, Statistical comparisons of half-width, rise time, quantal charge, and the probability of occurrence of a foot in the largest $10 \%$ of quantal ASs between astrocytes and RACCs. Error bars represent SEM.

$\mathrm{Ca}^{2+}$ imaging, cells were loaded with $2 \mu \mathrm{M}$ fura-2 AM and measured as described previously (Zhang and Zhou, 2002).

FM photoconversion and electron microscopy. FM photoconversion was performed as described previously (Harata et al., 2001). After FM staining, astrocytes cultured on coverslips were fixed with $2 \%$ glutaraldehyde in $100 \mathrm{~mm}$ sodium phosphate buffer (PB) for $20 \mathrm{~min}$ and washed with $100 \mathrm{~mm}$ glycine (in PB) for $1 \mathrm{~h}$. The coverslips were washed further in 100 $\mathrm{mm}$ ammonium chloride (in distilled water) for $5 \mathrm{~min}$. After brief rinsing in $\mathrm{PB}$, coverslips were incubated in $\mathrm{DAB}(1 \mathrm{mg} / \mathrm{ml}$ in $\mathrm{PB})$ for $10-20 \mathrm{~min}$. Fluorescence excitation light was then continuously applied for 10-20 min in DAB solution. For electron microscopy (EM), photoconverted astrocytes were osmium postfixed $\left(2 \% \mathrm{OsO}_{4}\right.$ in $\left.0.1 \mathrm{M} \mathrm{PBS}, \mathrm{pH} 7.3,4^{\circ} \mathrm{C}\right)$ for $1 \mathrm{~h}$ and dehydrated through an ascending series of acetone solutions. Dehydration was continued after staining and then the tissue was embedded in Epon. Thin serial sections $(60-80 \mathrm{~nm})$ were cut parallel to the coverslip surface and mounted on Formvar-coated slot grids. Grids were poststained with $2 \%$ aqueous uranyl acetate and Sato's lead citrate and examined on a JEM-1230 transmission electron microscope (Jeol, Tokyo, Japan).

\section{Results}

\section{Quantal secretion in astrocytes}

Hippocampal astrocytes were cultured from P1 Sprague Dawley rats (Zhang et al., 2003). As confirmed by immunostaining (Fig. $1 A$ ) and electrophysiology, astrocytes and neurons were distinguished by their morphologies. To record stimulus-induced quantal exocytosis by amperometry, astrocytes were preloaded 
with DA (Zhou and Misler, 1996; Kim et al., 2000; Zhang and Zhou, 2002). To increase the contact area between the cell and the CFE, the tip-polished sensor surface faced the flat membrane (Fig. $1 \mathrm{~A}$, diagram). Mstim is a well established method to selectively stimulate astrocytes in mixed glia-neuron cultures (Araque et al., 1999). As shown in Figure $1 A$, Mstim induced a rapid and sustained $\left[\mathrm{Ca}^{2+}\right]_{\mathrm{i}}$ increase followed by amperometric spikes (ASs) in the glia. The slow component of the amperometric current was induced by the remote release of large amounts of dopamine, which diffused to the CFE (Zhou and Misler, 1995b).

To compare the stimulus-induced glial ASs with classic ASs from chromaffin cells, CFE recordings from an astrocyte $(2 \mathrm{~s}$ Mstim) and a rat adrenal chromaffin cell (RACC) ( $0.2 \mathrm{~s}$ depolarization) were superimposed (Fig. $1 B$ ), giving similar profiles of latency distributions of AS events, except that the glial AS latency, defined as the time from the stimulus onset to an AS event, was 4.3 times longer (data not shown). Since the ASs of RACCs reflect established quantal events of single-vesicle release (Wightman et al., 1991; Chow et al., 1992; Alvarez de Toledo et al., 1993; Zhou and Misler, 1995a), the glial ASs should also represent quantal vesicular exocytosis. Among all ASs, vesicles immediately under the sensor surface give fast and large events, whereas vesicles distant from the sensor give slow and small events. The largest (and fastest) 10\% of ASs are those induced immediately under the sensor surface (Zhou and Misler, 1995a; Zhou et al., 1996). By analyzing the largest $10 \%$ of ASs, the half-width, rise time, total charge, and the probability of observing a "foot" were $54 \pm 3$ versus $6.9 \pm 0.7 \mathrm{~ms}, 7.7 \pm 0.9$ versus $2.2 \pm 0.1 \mathrm{~ms}, 4.3 \pm 0.2$ versus $0.6 \pm 0.1 \mathrm{pC}$, and 0.4 versus $36 \pm 6 \%$ for astrocytes and RACCs, respectively [the largest $10 \%$ of ASs from nine astrocytes (460 ASs) and from seven RACCs (650 ASs)] (Fig. 1C). The kinetics of glial ASs, however, had two distinct features. First, the rise time, quantal size, and half-width of glial ASs were much greater (Fig. 1C). For example, the half-width (54 ms) was 7.8 times that in RACCs. Second, compared with neurons (Bruns and Jahn, 1995), endocrine cells (Wightman et al., 1991; Chow et al., 1992), and mast cells (Alvarez de Toledo et al., 1993), glial ASs had very few events ( 2 of 564) in which a foot (transmitter prerelease from flickering fusion pores) preceded an individual major spike (Chow et al., 1992; Zhou et al., 1996), indicating that the astrocyte fusion pores are more rigid after opening (Fig. $1 B, C$ ). This distinct feature in glia is, however, fully consistent with the following reports: (1) instead of the fusion protein SNAP-25, astrocytes express SNAP-23 (Hepp et al., 1999); and (2) compared with SNAP-25, SNAP-23-mediated $\mathrm{Ca}^{2+}$-dependent ASs have reduced "feet" (Sorensen et al., 2003).

As indicated in Figure $1 B$, Mstim induced two classes of ASs from astrocytes: large (1-ASs) and small (s-ASs). Compared with the two l-ASs in Figure $1 B$, the s-AS has a 10-fold smaller current integral (or quantal size, corresponding to the number of molecules released from the vesicle), which may represent another class of vesicle release (see below).

\section{Partial vesicle release induced by physiological stimuli in cultured astrocytes}

Glutamate is an endogenous transmitter that activates metabotropic glutamate receptors to release $\mathrm{Ca}^{2+}$ from intracellular stores (data not shown). Local application of $0.5 \mathrm{~mm}$ glutamate (Schneggenburger et al., 1993; Zhou and Kimelberg, 2001) induced a burst of s-ASs in DA-loaded astrocytes (Fig. 2A). The s-ASs induced by glutamate (Fig. 2C) were 10-fold smaller than the l-ASs induced by Mstim (Fig. 2E). We then examined signal transmission between two astrocytes by stimulating glia 1 and
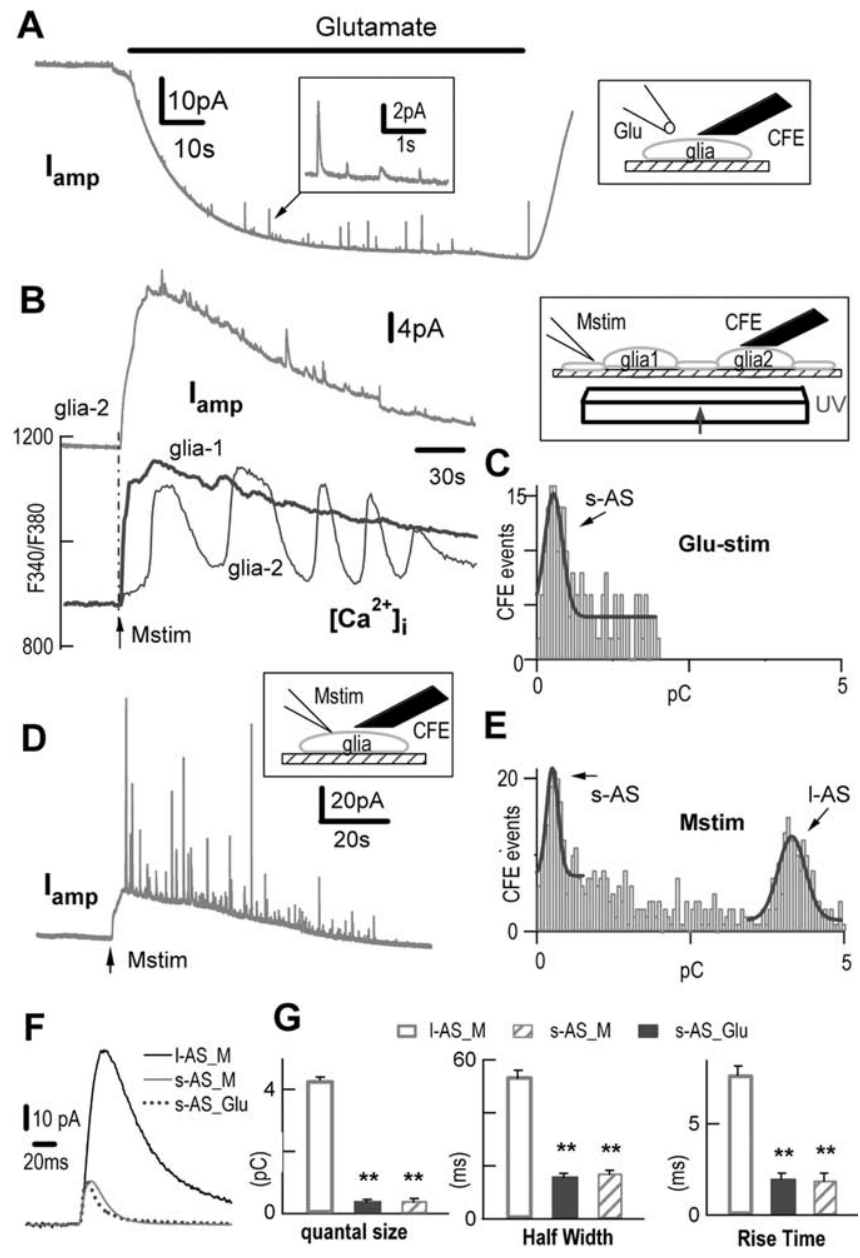

Figure 2. Evidence for kiss-and-run release from amperometry in astrocytes under physiological stimulation. $\boldsymbol{A}$, Glutamate $(0.5 \mathrm{~mm})$-induced amperometric spikes in an astrocyte $(n=$ 11). The slowly descending background current was an artifact caused by puffing glutamate (Zhou and Misler, 1995a). Inset, An AS burst. B, Stimulating glia 1 induced a $\left[\mathrm{Ca}^{2+}\right]_{i}$ increase in glia 1 (bottom trace, thick line) and caused $\left[\mathrm{Ca}^{2+}\right]_{\mathrm{i}}$ oscillations (bottom trace, thin line) and ASs (top trace) in glia $2(n=8)$. C, Quantal size distribution of Glu-stim-induced ASs and their Gaussian fit (214 ASs from 11 cells). $\boldsymbol{D}$, Mstim-induced ASs. $\boldsymbol{E}$, Quantal size distribution of Mstim-induced ASs and their Gaussian fit (726ASs from 18 cells). The two peaks represent the two AS classes, s-AS andI-AS(see also Fig.2A).F,Comparison ofs-AS andI-ASinduced by Mstim (s-AS_MandI-AS_M), ands-ASinduced by Glu-stim (s-AS_Glu) at an expanded time scale. G, Statistics. Corresponding to Mstim-induced I-ASS, Mstim-induced s-ASs, and Glu-stim-induced s-ASs, the quantal sizes were $4.3 \pm 0.1,0.4 \pm 0.1$, and $0.4 \pm 0.1 \mathrm{pC}$, the half-widths were $54 \pm 3,17 \pm 1$, and $16 \pm 1 \mathrm{~ms}$, and the rise times were $7.7 \pm$ $0.5,1.9 \pm 0.4$, and $2.0 \pm 0.3 \mathrm{~ms}$, respectively. Diagrams in $\boldsymbol{A}, \boldsymbol{B}$, and $\boldsymbol{D}$ illustrate the setup for each experiment. Error bars represent SEM.

observing the responses in adjacent glia 2 (Fig. $2 \mathrm{~B}$, diagram). Mstim induced a sustained $\left[\mathrm{Ca}^{2+}\right]_{\mathrm{i}}$ elevation in glia 1 , followed by ASs and $\mathrm{Ca}^{2+}$ waves in glia 2 (Fig. $2 \mathrm{~B}$ ). This result in cultured astrocytes is consistent with the calcium wave seen in astrocytes in brain slices (Parri et al., 2001). Figure 2, $C$ and E, shows the quantal size distributions of Glu-stim- and Mstim-induced ASs, respectively. The histogram of Glu-stim-induced ASs has a single peak at $0.4 \mathrm{pC}$. However, the histogram of Mstim-induced ASs gives two distinct peaks at 0.4 and $4.3 \mathrm{pC}$, corresponding to the $\mathrm{s}$-ASs and 1-ASs shown in Figure $1 B$. Interestingly, the ASs induced by Glu-stim and the s-ASs induced by Mstim are virtually identical in both quantal size and kinetics (Fig. $2 F, G$ ), indicating that they belong to the same class of vesicle release. The fact that two classes of ASs were induced by Mstim, but not Glu-stim, suggests that l-ASs need the sustained high $\left[\mathrm{Ca}^{2+}\right]_{\mathrm{i}}$ that is in- 

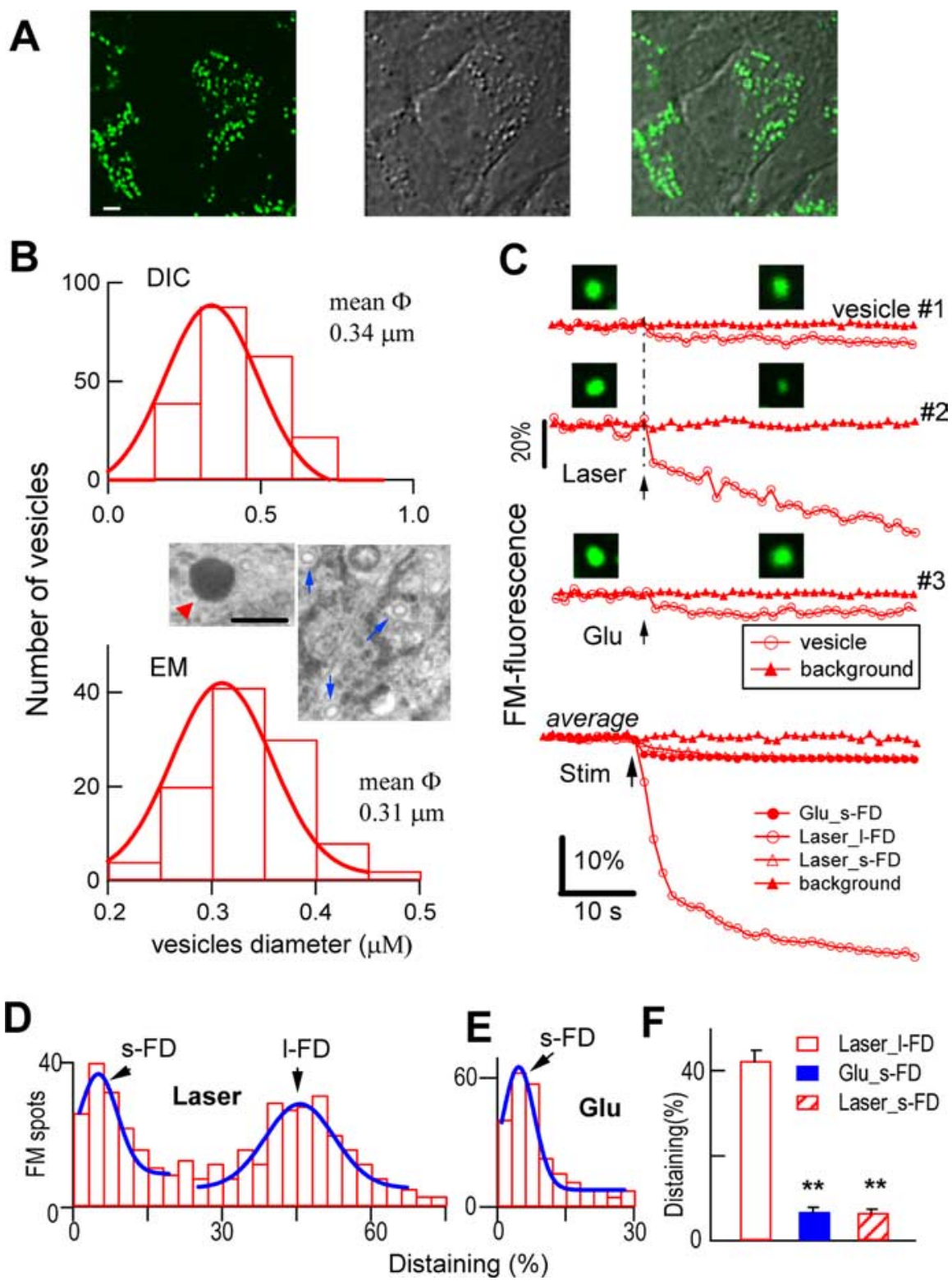

Figure 3. Evidence for kiss-and-run release from FM imaging in cultured astrocytes under physiological stimulation. $A$, Confocal images. Left, FM fluorescence; middle, DIC; right, merged. Scale bar, $2 \mu \mathrm{m}$. B, Diameter distribution and Gaussian fit curves of FM-loaded vesicles. Spot diameters under DIC (top) and EM (bottom). Insets, Glial vesicles stained by FM and photoconverted for EMs from an astrocyte. Scale bar, $300 \mathrm{~nm}$. The red arrow indicates a photoconverted vesicle (left); the blue arrows indicate small vesicles (right). C, Time course of FM destaining from three representative single vesicles induced by laser (vesicle \#1 for s-FD, \#2 for $1-F D$ ), or $100 \mu \mathrm{m}$ glutamate (vesicle\#3, s-FD). The vesicle images before and after the FM discharge are placed near the imaging time on the traces. Fluorescence signals of FM discharge from single vesicles and nearby background are marked as circles and triangles, respectively. The bottom panel shows average traces of 393 vesicles from 14 cells with laser stimulation and 243 vesicles from 11 cells with glutamate stimulation. D, FM destaining distribution of vesicles induced by laser and their Gaussian fits (393 vesicles from 14 cells). The two peaks represent the two FD classes, s-FD and I-FD. E, FM destaining distribution of Glu-stiminduced FD and their Gaussian fit (243 vesicles from 11 cells). $\boldsymbol{F}$, Histogram of percentage of FM destaining in vesicles similar to those in $\mathbf{C}$ at $25 \mathrm{~s}$ after the onset of stimulation. Error bars represent SEM.

duced by the nonphysiological Mstim. In contrast, in addition to quantal size, the rise time and half-width of s-ASs were also three to four times smaller than those of l-ASs (Fig. 2G). The three recordings of representative s-ASs and l-ASs show that the two s-ASs have similar kinetics; however, the decay of the l-AS is very different from the decay of the s-ASs. Note that the rising phase of thel-AS and the s-AS are nearly identical, implying that the DA release was from two vesicles with similar kinetics of fusion to the plasma membrane (Fig. 2F).
The two AS classes induced by Mstim may come from either two kinds of vesicles with different content sizes or from a single type of vesicle releasing its contents under two modes, full fusion and kiss-andrun, as for neuronal vesicles (Zhou et al., 1996; Aravanis et al., 2003; Staal et al., 2004). To determine whether kiss-andrun release is responsible for the s-ASs, single vesicles were visualized by twophoton imaging in astrocytes preloaded with the fluorescent dye FM 1-43 (Angleson et al., 1999; Aravanis et al., 2003). Because cultured astrocytes have a flat morphology, individual vesicles were clearly visible in both fluorescence and differential interference contrast (DIC) transmission images (Fig. 3A). Surprisingly, most DIC-visible vesicles were FM loaded, indicating that most of the vesicles experienced endocytosis/FM loading during the preloading process. The distribution of vesicle diameters gave a single peak as measured by DIC and EM (photoconverted FM-loaded vesicle) images, indicating that FM dye was loaded into only one type of vesicle. The average vesicle diameters measured from DIC and EM images were $340 \pm 9$ and $310 \pm 22 \mathrm{~nm}$, respectively (Fig. $3 B, C$ ). The diameter distributions of FM 1-43 spots had similar single peak as well, except that the peak was at $810 \mathrm{~nm}$ (data not shown). According to calibration of fluorescence beads, the apparent larger (2.4-fold) size of FM spots was attributable to the fluorescence diffraction effect (data not shown). This confirmed that each FM-loaded fluorescent spot represented a single vesicle. To minimize focus errors of FM imaging caused by mechanical disturbance, Mstim was replaced by applying a brief laser beam $(800$ $\mathrm{nm}, 25 \mathrm{~ms}, 0.5 \mathrm{~mW}$ ) of $0.25 \times 0.25 \mu \mathrm{m}^{2}$ to the astrocyte. Similar to nonphysiological Mstim, the laser also induced a sustained $\left[\mathrm{Ca}^{2+}\right]_{\mathrm{i}}$ increase. In contrast, glutamate $(0.1 \mathrm{~mm})$ application was used as the Glustim. The time courses of release from two representative vesicles, which showed laser-induced small and large FM fluorescence destaining (s-FD and l-FD, respectively), and from a typical glutamateinduced FM destaining, are illustrated in Figure $3 C$. The distribution of laser-induced single-vesicle destaining contained two distinct peaks at 7\% (s-FD) and 43\% (l-FD) (Fig. 3D). In contrast, the distribution of glutamateinduced vesicle destaining had only a single peak at 7\% (Fig. $3 E$ ), which matched the laser-induced s-FD. These FM imaging data are entirely consistent with the amperometric results, with s-FD and l-FD corresponding to s-AS and l-AS. These data strongly suggest that FM-loaded vesicles are the same ones loaded by dopamine shown in Figures 1-3. 
We also examined the effects of two subsequent stimulations by glutamate and laser on the FM 2-10 destaining in the same vesicle (Fig. 4A, left). FM 2-10 has a faster destaining rate than that of FM 1-43 ( $\tau_{\text {off }}=0.6$ vs $2.5 \mathrm{~s}$ ) (Ryan et al., 1996; Klingauf et al., 1998). Statistically, a single vesicle destained $5.4 \pm 1.2 \%$ in response to the first stimulation (glutamate for $10 \mathrm{~s}$ ), and the same vesicle destained $45 \pm 3 \%$ in response to the second stimulation (Mstim-like laser) (Fig. 4A, right). This experiment provides direct and compelling evidence that (1) a single vesicle releases only $5 \%$ of its total FM content after physiological stimulation; and (2) the same vesicle can release nine times as much after very strong stimulation. Note that the onset of FM destaining took $2 \mathrm{~s}$, which was considerably longer than the half duration ( $60 \mathrm{~ms}$ ) of a l-AS detected by CFE, probably because of the slow dissociation constant of the FM dye (0.6 s for FM 2-10) (Klingauf et al., 1998).

\section{Glutamate is the glial transmitter}

Subsequently, we showed that glutamatecontaining vesicles are the same vesicles as those loaded with FM 1-43, illustrated in Figures 3 and 4 . We double-labeled the vesicles using a fixable FM 1-43 analog, AM1-43 (Renger et al., 2001), and anti-glutamate antibody (Carder and Hendry, 1994). As shown in Figure 4B, 87\% of AMlabeled vesicles were glutamate positive. On average, the antiglutamate antibody and AM1-43 colocalization was $66 \pm 7 \%$ $(n=8)$. Thus, the releasable vesicles underlying the different kinds of stimulation were glutamate-releasing vesicles.

\section{Glial quantal release is $\mathrm{Ca}^{2+}$ and SNARE dependent}

Combined CFE and $\left[\mathrm{Ca}^{2+}\right]_{\mathrm{i}}$ measurements were applied in single astrocytes to determine the $\mathrm{Ca}^{2+}$ dependence during a Mstim-induced sustained $\left[\mathrm{Ca}^{2+}\right]_{\mathrm{i}}$ elevation and ASs. The frequency of ASs and $\left[\mathrm{Ca}^{2+}\right]_{\mathrm{i}}$ were reduced by $77 \pm 7$ and $63 \pm 8 \%$ when external $\mathrm{Ca}^{2+}$ was changed from $2 \mathrm{~mm}$ to $0(n=7)$ (Fig. $5 A$ ). The same $\mathrm{Ca}^{2+}$ dependence was observed with chemical stimulation, when the $\mathrm{Ca}^{2+}$ ionophore ionomycin $(10 \mu \mathrm{M})$ was puffed onto the astrocytes (Fig. 5B). Finally, combined measurements of FM and fura-2 confirmed that laser-induced FM destaining from glial vesicles (revealed by FM) was $\mathrm{Ca}^{2+}$ dependent (revealed by F380) (Fig. 5C). In $2 \mathrm{mM}\left[\mathrm{Ca}^{2+}\right]_{\mathrm{o}}$, the stimulation reduced F380 and FM by $56 \pm 4 \%$ (108 images from eight cells) and $42 \pm 3 \%$ (308 vesicle images from 12 cells), respectively. In contrast, the laser caused little change in F380 and FM in $0\left[\mathrm{Ca}^{2+}\right]_{\mathrm{o}}$. These data demonstrate that stimulus-induced quantal secretion depends on $\left[\mathrm{Ca}^{2+}\right]_{\mathrm{i}}$ in astrocytes.

Fusion proteins are required for $\mathrm{Ca}^{2+}$-dependent exocytosis in neurons and other cells (Jahn and Sudhof, 1999). To test whether the fusion protein complex SNARE is involved in quantal secretion in astrocytes, TeNT, a specific toxin against SNARE (Xu et al., 1998), was introduced into astrocytes and RACCs (positive control). In astrocytes, TeNT significantly inhibited Mstiminduced ASs by $44 \pm 6 \%$ (71 cells for control, 40 cells for TeNT; $p<0.01$ ) (Fig. 5D) (Pasti et al., 2001). In RACCs, $79 \pm 3 \%$ of secretion was inhibited by TeNT ( 79 cells for control, 58 cells for
TeNT; $p<0.01$ ) (Xu et al., 1998). The different efficiencies of tetanus toxin in suppressing secretion in chromaffin cells and astrocytes may come from the different combinations of fusion proteins in the two kinds of cell (Sorensen et al., 2003; Zhang et al., 2004). These data indicate that SNARE is involved in quantal secretion from astrocytes.

\section{Partial vesicle release in freshly isolated astrocytes}

Thus far, the results are consistent with hypothesis that release of glutamate from cultured astrocytes was by the kiss-and-run mode. However, long-term culture (2-3 weeks) may cause the artificial expression of some proteins, such as $\mathrm{Ca}^{2+}$-permeable AMPA receptors (Janssens and Lesage, 2001). To determine whether the glutamate quantal release is an artifact of culture, we examined the laser-stimulated FM destaining in freshly isolated astrocytes (FIAs) (Zhou and Kimelberg, 2000, 2001). FIAs were identified by a soma with an oval, elongated, or triangular shape and with multiple, long, bushy processes extending from the cell body (Fig. 6A, right). After the standard FM destaining experiments, we also retrospectively stained with GFAP to confirm the identity of each cell as an astrocyte (Fig. 6A, middle). Under DIC imaging, vesicles in the processes of FIA could be clearly identified and had similar diameters to those in cultured astrocytes (Fig. 6B). The diameter distributions of FM 1-43 spots had a similar single peak as well, except that the peak was at $780 \mathrm{~nm}$ (data not shown). (The apparent larger size of FM spots is attributable to the fluorescence dispersion effect.) By applying the laser stimulation protocol of Figure 3 to FIAs, the FM-loaded vesicles showed an FM destaining distribution with two populations $(6.2 \pm 1.5 \%$ for s-FD and $45.5 \pm 6.3 \%$ for $1-F D$ ) (Fig. $6 C-E$ ), and the ratio of s-FD to $1-F D(\sim 1: 7.5)$ was also similar to that in cultured astrocytes (Fig. 3). Thus, the partial vesicular release also occurs in FIAs. 
A
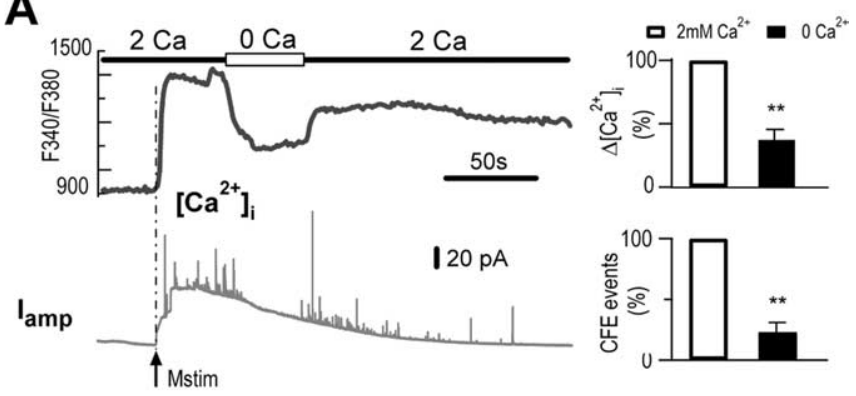

B
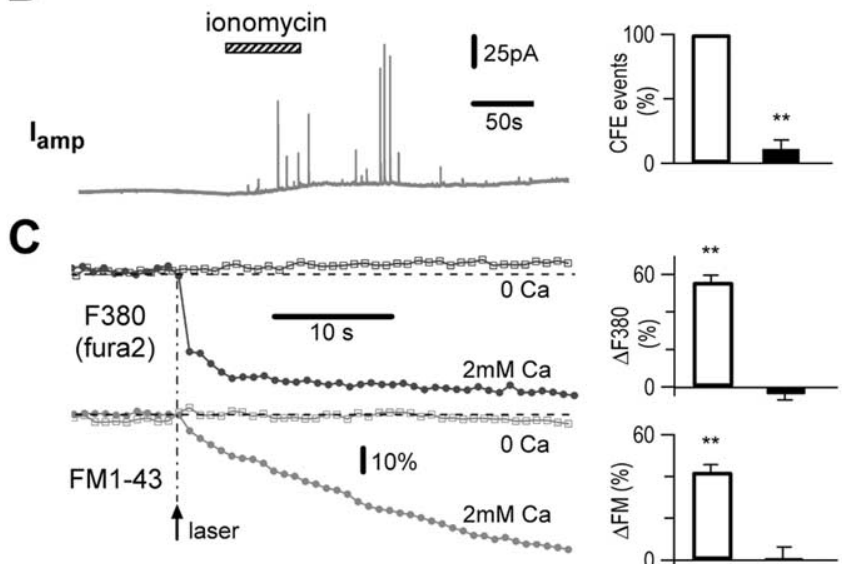

D
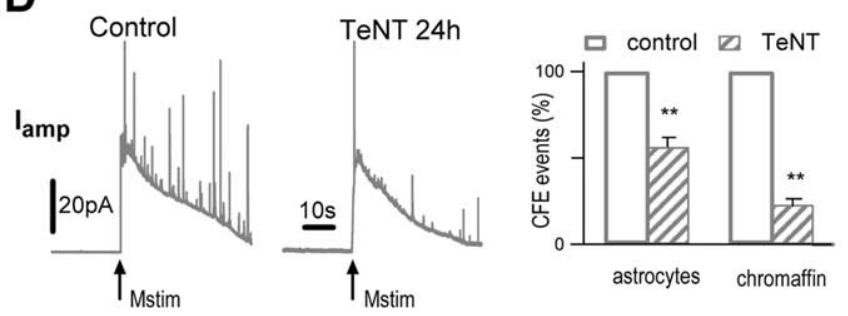

Figure 5. Stimulus-induced ASs are dependent on $\mathrm{Ca}^{2+}$ and SNARE. $\boldsymbol{A}, \mathrm{Ca}^{2+}$ dependence of amperometric spikes. Left, Mstim-induced $\left[\mathrm{Ca}^{2+}\right]_{i}$ and $A S s\left(I_{\text {amp }}\right)$ at 2 mm versus $0\left[\mathrm{Ca}^{2+}\right]_{0}$. Right, Statistics. $\boldsymbol{B}$, lonomycin-induced ASs in $2 \mathrm{~mm}\left[\mathrm{Ca}^{2+}\right]_{0}$ (left). ASs were reduced by $89 \pm$ $8 \%$ in $0\left[\mathrm{Ca}^{2+}\right]_{0}$ (right; $p<0.01 ; n=5$ ). C, Laser-induced destaining of FM 1-43 was $\mathrm{Ca}^{2+}$ dependent. Left, $\mathrm{Ca}^{2+}$-sensitive F380 and FM 1-43 at 2 mu (filled symbols) versus $0\left[\mathrm{Ca}^{2+}\right]_{0}$ (open symbols). Right, Statistics. D, ASs were inhibited by tetanus toxin (control vs TeNT). Right, Statistics. All experiments were from three batches of astrocytes and three batches of RACCs. Error bars represent SEM.

\section{Discussion}

Kiss-and-run as the release mechanism in astrocytes

The most important finding in the present work is that a glial vesicle releases only part $(\sim 10 \%)$ of its total vesicle content during a release event triggered by physiological stimulation. The partial release is termed as kiss-and-run. This conclusion is supported by the following experimental evidence: (1) In quantal content distribution, Mstim induced two populations of amperometric spikes, the s-ASs and l-ASs, with quantal release contents of 1:10 (Fig. 2). (2) Glu-stim-induced ASs comprised only one population, which was equivalent to the Mstim-induced s-AS (Fig. 2). (3) There were two populations of Mstim-induced FM destaining from single vesicles, s-FD and l-FD, with quantal release contents of 1:9 (Fig. 3). (4) Glu-stim-induced FDs comprised only one population, which was equivalent to the Mstiminduced s-FDs (Fig. 3). (5) Single-vesicle FM imaging revealed that, although initial Glu-stim induced a s-FD, a subsequent
Mstim-like laser pulse induced a l-FD from the same vesicle (Fig. 4A). (6) The distribution of vesicle sizes (both by DIC and EM imaging) gave only a single vesicle population (Fig. $3 B$ ), excluding the possibility that s-AS and l-AS were from small and large vesicles, respectively. (7) The distributions of Mstim- and Glustim-induced release of quantal contents were virtually same for ASs and FDs, indicating that AS and FD were from the same kind of vesicle (Figs. 2, 3). (8) Glutamate was colocalized with FM dyes, indicating that the FM release and glutamate release were from the same kind of vesicle (Fig. 4B). (9) Two populations of Mstim-induced FM destaining from single vesicles were also found in freshly isolated astrocytes (Fig. 6). Furthermore, although the rising phases of the l-AS and the s-AS were nearly identical, the s-AS decayed twice as fast as the 1-AS (Fig. 2 F). Following the kiss-and-run hypothesis, we propose that the rapid decay in s-ASs was caused by the fusion pore closing before release of the major content. In other words, the rise time of the s-AS was equal to the open time of the fusion pore $(2.0 \pm 0.3 \mathrm{~ms})$, whereas the slower decay of the l-AS was attributable to vesicle release during a full (or at least more complete) fusion event.

The advantage of kiss-and-run release is that a single vesicle can release transmitter multiple times after multiple stimulations, providing an efficient means of exocytosis with a limited number of release vesicles. This mechanism has been found in endocrine cells (Zhou et al., 1996) and neurons (Aravanis et al., 2003; Staal et al., 2004). However, because the glial vesicle size $(310 \mathrm{~nm})$ is much larger than that in RACCs $(125 \mathrm{~nm}$; data not shown) and synapses (50-100 $\mathrm{nm})$, the fractional release during each fusion is much smaller in astrocytes ( $<5 \%$ of total FM dye) (Fig. 4) than that in chromaffin cells [ $>80 \%$ of total transmitter (Zhou et al., 1996)] and synapses [30\% of total transmitter for DA neurons (Staal et al., 2004); 47\% of total FM dye for hippocampal neurons (Aravanis et al., 2003)], permitting more rounds of release in a short time before refilling of the glial vesicles. Assuming that the vesicle releases $10 \%$ of its dopamine contents during each round (Fig. 2), after 10 rounds, $35 \%$ of the original dopamine content still remains. According to diffusion theory (Pusch and Neher, 1988), the release rate is dependent on molecular weight (release rate, $k \times M^{-1 / 3}$, where $M$ is the molecular weight of the released substance and $k$ is a constant). Given the similar molecular weights of dopamine $(170 \mathrm{Da})$ and glutamate $(147 \mathrm{Da})$, if both molecules are free to diffuse from the vesicles, the $10 \%$ dopamine release per exocytotic event should also apply to glutamate in astrocytes.

Our findings suggest that two distinct exocytotic modes correspond to physiological stimulation and nonphysiological stimulation. Kiss-and-run is the exocytotic mode for physiological stimulation, whereas strong stimulation induced by Mstim or laser causes the exocytotic mode of permanent vesicle fusion, during which most/all vesicle contents are released. The dependence of vesicle fusion mode on stimulus/ $\mathrm{Ca}^{2+}$ has been reported previously by others and by us in chromaffin cells (Zhou et al., 1996; Ales et al., 1999). In addition, different isoforms of synaptotagmin have been reported as underlying different modes of vesicle fusion. Synaptotagmin I is for full fusion, and synaptotagmin IV is for kiss-and-run (Wang et al., 2003). Recently, synaptotagmin IV was found to be expressed exclusively in astrocytes for glutamate release (Zhang et al., 2004). Future work should address which fusion protein is responsible for kiss-and-run fusion in astrocytes. 


\section{Single flicker fusion pore}

In chromaffin cells and DA neurons, in which kiss-and-run is characterized by transmitter release during rapid fusionpore flickering, the fusion pore switches on and off multiple times within a second (Zhou et al., 1996; Ales et al., 1999; Staal et al., 2004). Surprisingly, in astrocytes, although only a small portion of the total content was released after physiological stimulation, there was little detectable fusion pore flickering (very few foot events). As revealed by direct measurement with FM imaging, Glu-stim triggered only a partial release of the vesicle content (Fig. $4 A$ ). Interestingly, few feet or repeated fusion pore flickers occurred during each release event in astrocytes. Thus, the kissand-run in astrocytes is distinct from that in neuronal cells: it is a "single kiss" or "single flicker." The molecular mechanism of "single-kiss-and-run" in astrocytes is unclear, but it may be related to distinct fusion proteins including SNAP-23, which differs from the SNAP-25 in neurons (Parpura et al., 1995; Hepp et al., 1999; Sorensen et al., 2003).

What type of vesicle is responsible for the glutamate release?

Comparing the properties of quantal vesicle release in astrocytes and chromaffin cells, the two cell types differ in their kinetics and fusion protein subunits. Consistent with the large size of glial vesicles $(310 \mathrm{~nm}$ in diameter), the quantal event in glia is much larger and wider than that in neurons and endocrine cells but similar to that in mast cells. This result differed from those of Bezzi et al. (2004), who identified the vesicular glutamate transporter (VGluT)positive vesicle with small size $(\sim 30 \mathrm{~nm}$ in diameter) in brain slices. However, it is not clear whether the exocytotic vesicles that were evoked were these small vesicles. It seems, rather, that their exocytotic vesicles were large ( $\sim 700 \mathrm{~nm}$ in diameter for their GFP fluorescent spots). This spot size is far larger than the $30 \mathrm{~nm}$ vesicles seen in the slice, but similar to the FM fluorescent spots in our cultured and freshly isolated astrocytes. In contrast, our single-vesicle FM imaging showed that all $\mathrm{Ca}^{2+}$-triggered exocytosis was from large $(310 \mathrm{~nm})$ vesicles. Thus, we propose that large vesicles (310 $\mathrm{nm}$ diameter), but not small vesicles $(30 \mathrm{~nm})$, are responsible for the $\mathrm{Ca}^{2+}$-dependent vesicle release in cultured and freshly isolated astrocytes.

\section{References}

Ales E, Tabares L, Poyato JM, Valero V, Lindau M, Alvarez de Toledo G (1999) High calcium concentrations shift the mode of exocytosis to the kiss-and-run mechanism. Nat Cell Biol 1:40-44.

Alvarez de Toledo G, Fernandez-Chacon R, Fernandez JM (1993) Release of secretory products during transient vesicle fusion. Nature 363:554-558.

Angleson JK, Cochilla AJ, Kilic G, Nussinovitch I, Betz WJ (1999) Regulation of dense core release from neuroendocrine cells revealed by imaging single exocytic events. Nat Neurosci 2:440-446.
A $\quad$ FM1-43
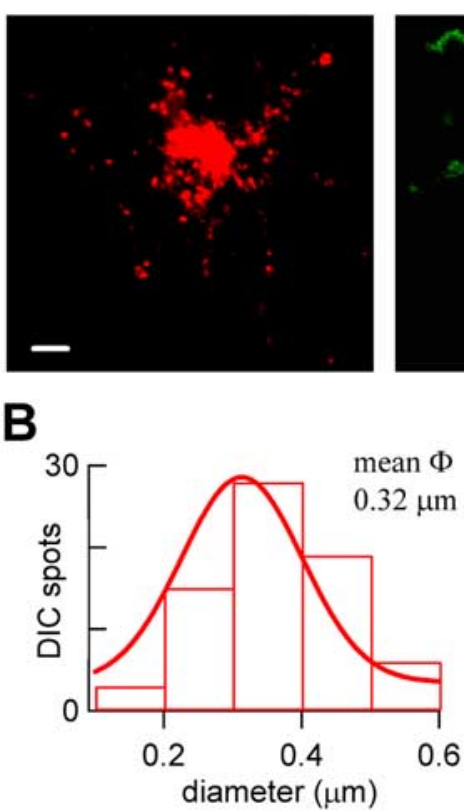

D

Figure 6. FM imaging of kiss-and-run vesicle release in freshly isolated astrocytes. $A, A$ typical FIA for single-vesicle FM imaging. Left, The FIA loaded with FM; middle, the FIA examined by GFAP immunostaining after FM destaining; right, DIC image. Scale bar, $5 \mu \mathrm{m}$. Without the laser stimulation, the GFAP immunoreactivity was distributed in distinct fibers (data not shown). B and I-FD. $\boldsymbol{E}$, The percentage destaining of s-FD and I-FD were $6 \pm 2$ and $46 \pm 6 \%$, respectively. Error bars represent SEM.
Araque A, Parpura V, Sanzgiri RP, Haydon PG (1999) Tripartite synapses: glia, the unacknowledged partner. Trends Neurosci 22:208-215.

Aravanis AM, Pyle JL, Tsien RW (2003) Single synaptic vesicles fusing transiently and successively without loss of identity. Nature 423:643-647.

Bezzi P, Volterra A (2001) A neuron-glia signalling network in the active brain. Curr Opin Neurobiol 11:387-394.

Bezzi P, Gundersen V, Galbete JL, Seifert G, Steinhauser C, Pilati E, Volterra A (2004) Astrocytes contain a vesicular compartment that is competent for regulated exocytosis of glutamate. Nat Neurosci 7:613-620.

Bruns D, Jahn R (1995) Real-time measurement of transmitter release from single synaptic vesicles. Nature 377:62-65.

Carder RK, Hendry SH (1994) Neuronal characterization, compartmental distribution, and activity-dependent regulation of glutamate immunoreactivity in adult monkey striate cortex. J Neurosci 14:242-262.

Carmignoto G (2000) Reciprocal communication systems between astrocytes and neurones. Prog Neurobiol 62:561-581.

Chow RH, von Ruden L, Neher E (1992) Delay in vesicle fusion revealed by electrochemical monitoring of single secretory events in adrenal chromaffin cells. Nature 356:60-63.

Fields RD, Stevens-Graham B (2002) New insights into neuron-glia communication. Science 298:556-562.

Harata N, Ryan TA, Smith SJ, Buchanan J, Tsien RW (2001) Visualizing recycling synaptic vesicles in hippocampal neurons by FM 1-43 photoconversion. Proc Natl Acad Sci USA 98:12748-12753. 
Haydon PG (2001) GLIA: listening and talking to the synapse. Nat Rev Neurosci 2:185-193.

Hepp R, Perraut M, Chasserot-Golaz S, Galli T, Aunis D, Langley K, Grant NJ (1999) Cultured glial cells express the SNAP-25 analogue SNAP-23. Glia 27:181-187.

Jahn R, Sudhof TC (1999) Membrane fusion and exocytosis. Annu Rev Biochem 68:863-911.

Janssens N, Lesage AS (2001) Glutamate receptor subunit expression in primary neuronal and secondary glial cultures. J Neurochem 77:1457-1474.

Kim KT, Koh DS, Hille B (2000) Loading of oxidizable transmitters into secretory vesicles permits carbon-fiber amperometry. J Neurosci 20:RC101(1-5).

Klingauf J, Kavalali ET, Tsien RW (1998) Kinetics and regulation of fast endocytosis at hippocampal synapses. Nature 394:581-585.

Parpura V, Fang Y, Basarsky T, Jahn R, Haydon PG (1995) Expression of synaptobrevin II, cellubrevin and syntaxin but not SNAP-25 in cultured astrocytes. FEBS Lett 377:489-492.

Parri HR, Gould TM, Crunelli V (2001) Spontaneous astrocytic $\mathrm{Ca}^{2+}$ oscillations in situ drive NMDAR-mediated neuronal excitation. Nat Neurosci 4:803-812.

Pasti L, Zonta M, Pozzan T, Vicini S, Carmignoto G (2001) Cytosolic calcium oscillations in astrocytes may regulate exocytotic release of glutamate. J Neurosci 21:477-484.

Pusch M, Neher E (1988) Rates of diffusional exchange between small cells and a measuring patch pipette. Pflügers Arch 411:204-211.

Renger JJ, Egles C, Liu G (2001) A developmental switch in neurotransmitter flux enhances synaptic efficacy by affecting AMPA receptor activation. Neuron 29:469-484.

Ryan TA, Smith SJ, Reuter H (1996) The timing of synaptic vesicle endocytosis. Proc Natl Acad Sci USA 93:5567-5571.

Schneggenburger R, Zhou Z, Konnerth A, Neher E (1993) Fractional contribution of calcium to the cation current through glutamate receptor channels. Neuron 11:133-143.

Sorensen JB, Nagy G, Varoqueaux F, Nehring RB, Brose N, Wilson MC, Neher E (2003) Differential control of the releasable vesicle pools by SNAP-25 splice variants and SNAP-23. Cell 114:75-86.

Staal RG, Mosharov EV, Sulzer D (2004) Dopamine neurons release transmitter via a flickering fusion pore. Nat Neurosci 7:341-346.

Ullian EM, Sapperstein SK, Christopherson KS, Barres BA (2001) Control of synapse number by glia. Science 291:657-661.
Wang CT, Lu JC, Bai J, Chang PY, Martin TF, Chapman ER, Jackson MB (2003) Different domains of synaptotagmin control the choice between kiss-and-run and full fusion. Nature 424:943-947.

Wightman RM, Jankowski JA, Kennedy RT, Kawagoe KT, Schroeder TJ, Leszczyszyn DJ, Near JA, Diliberto Jr EJ, Viveros OH (1991) Temporally resolved catecholamine spikes correspond to single vesicle release from individual chromaffin cells. Proc Natl Acad Sci USA 88:10754-10758.

Xu T, Binz T, Niemann H, Neher E (1998) Multiple kinetic components of exocytosis distinguished by neurotoxin sensitivity. Nat Neurosci 1:192-200.

Yang Y, Ge W, Chen Y, Zhang Z, Shen W, Wu C, Poo M, Duan S (2003) Contribution of astrocytes to hippocampal long-term potentiation through release of D-serine. Proc Natl Acad Sci USA 100:15194-15199.

Zhang C, Zhou Z (2002) Ca(2+)-independent but voltage-dependent secretion in mammalian dorsal root ganglion neurons. Nat Neurosci 5:425-430.

Zhang JM, Wang HK, Ye CQ, Ge W, Chen Y, Jiang ZL, Wu CP, Poo MM, Duan S (2003) ATP released by astrocytes mediates glutamatergic activity-dependent heterosynaptic suppression. Neuron 40:971-982.

Zhang Q, Fukuda M, Van Bockstaele E, Pascual O, Haydon PG (2004) Synaptotagmin IV regulates glial glutamate release. Proc Natl Acad Sci USA 101:9441-9446.

Zhou M, Kimelberg HK (2000) Freshly isolated astrocytes from rat hippocampus show two distinct current patterns and different $[K(+)](\mathrm{o})$ uptake capabilities. J Neurophysiol 84:2746-2757.

Zhou M, Kimelberg HK (2001) Freshly isolated hippocampal CA1 astrocytes comprise two populations differing in glutamate transporter and AMPA receptor expression. J Neurosci 21:7901-7908.

Zhou Z, Misler S (1995a) Action potential-induced quantal secretion of catecholamines from rat adrenal chromaffin cells. J Biol Chem 270: 3498-3505.

Zhou Z, Misler S (1995b) Amperometric detection of stimulus-induced quantal release of catecholamines from cultured superior cervical ganglion neurons. Proc Natl Acad Sci USA 92:6938-6942.

Zhou Z, Misler S (1996) Amperometric detection of quantal secretion from patch-clamped rat pancreatic beta-cells. J Biol Chem 271:270-277.

Zhou Z, Misler S, Chow RH (1996) Rapid fluctuations in transmitter release from single vesicles in bovine adrenal chromaffin cells. Biophys J 70: 1543-1552. 